\title{
Evidence against the use of fecal pellet size for age determination in European wild rabbits
}

\author{
Carlos Rouco $^{\mathrm{a}, \mathrm{b}, *}$, Miguel Delibes-Mateos ${ }^{\mathrm{b}, \mathrm{c}}$, Sacramento Moreno $^{\mathrm{a}}$ \\ ${ }^{a}$ Estación Biológica de Doñana-CSIC, Avda. Américo Vespucio s/n, 41092 Seville, Spain \\ ${ }^{\mathrm{b}}$ Instituto de Investigación en Recursos Cinegéticos, IREC (CSIC-UCLM-JCCM), Ronda de Toledo s/n, 13071 Ciudad Real, Spain \\ ${ }^{c}$ Department of Ecology and Natural Resource Management, Norwegian University of Life Sciences, Box 5003, NO-1432 As, Norway
}

Keywords:

Aging methodology

Oryctolagus cuniculus

Pellet count

Rabbit capture

\section{a b s t r a c t}

Techniques for estimating the age of wild animals are crucial to many aspects of the study of population biology. Accurate estimates of the proportion of different age classes in wild rabbit populations would be very useful, and the possibility that it could be obtained from the pellet size holds great appeal. However, this suggestion has created controversy in the literature as this technique has not been validated. This study involved assessment of whether threshold fecal pellet diameters could be used to differentiate adult and juvenile rabbits. The proportion of adults in four wild rabbit populations living in semi-natural conditions was compared with the proportion of animal pellets greater than threshold diameters of $6 \mathrm{~mm}$ and $4 \mathrm{~mm}$. Our results suggest that inferring a relationship between the proportion of pellets $>6 \mathrm{~mm}$ diameter and the proportion of adults in a population is not applicable to European wild rabbits, and that the use of this method could produce erroneous interpretations. The use of a $4 \mathrm{~mm}$ pellet diameter threshold appeared to produce even more inaccurate results. Studies that use this technique should include validation, as the results can vary greatly among individuals and populations.

\section{Introduction}

Obtaining information about wild mammal populations is a long-standing logistical problem, and an array of noninvasive techniques and effective indices are key to the overall success of any monitoring program. One of the most widely used approaches to monitoring population numbers in several mammal species is counting of scat, spraint or pellets (Kruuk et al., 1986; Murray et al., 2002; Webbon et al., 2004). Ecological indices need to reflect the complexities of the subject matter under study, yet remain simple enough to be easily and routinely monitored. The development of new ecological indices tends to lead to important scientific debates about their effectiveness, and this is the case with respect to the accuracy of noninvasive methods for age determination, such as the size of footprints or feces (e.g. Southgate, 2005).

Such a debate currently exists about the appropriateness of using fecal pellet size to determine the age of European wild rabbits (Oryctolagus cuniculus). Simonetti and Fuentes (1982) reported that

\footnotetext{
* Corresponding author at: Estación Bioló gica de Doñana - CSIC, Avd. Américo Vespucio s/n, 41092 Seville, Spain. Tel.: p34 9544667 00; fax: p34 954621125. E-mail addresses: c.rouco@gmail.es, c.rouco@ebd.csic.es (C. Rouco).
}

the diameter of fecal pellets was positively correlated with the size, and presumably age, of the rabbits producing them, but no detail of the analyses undertaken was provided. Similarly, Bhadresa (1982) suggested that pellet weight might be used in New Zealand white rabbits to determine rabbit age. Rueda (2006), Dellafiore (2007) and Rueda et al. (2008) subsequently used a method based on pellet size to differentiate adult and juvenile rabbits. These authors considered that pellets $>6 \mathrm{~mm}$ in diameter were deposited by adults, while those $<6 \mathrm{~mm}$ in diameter were deposited by juveniles or kittens. Delibes-Mateos et al. (2009) refuted the accuracy of this method by experimentally showing that adult rabbits produced similar proportions of pellets in each size class. However, Rueda et al. (2009) questioned these results, suggesting that the experimental design of Delibes-Mateos et al. (2009) was not suitable for testing the usefulness of their method. In the present study, we further assess the validity of using a $6 \mathrm{~mm}$ fecal pellet diameter as a threshold for differentiating adult and juvenile rabbits, following the recommendations of Rueda et al. (2009). Specifically, the proportion of adults in four wild rabbit populations living in seminatural conditions was compared with the proportion of pellets greater than $6 \mathrm{~mm}$ that were produced by the animals. We undertook a similar analysis based on a threshold pellet diameter of $4 \mathrm{~mm}$. 


\section{Material and methods}

\subsection{Rabbit populations}

We surveyed four rabbit populations in a restocking program carried out during spring 2008 in the Hornachuelos Natural Park (southern Spain). The area is characterized by a Mediterranean climate, and the main habitat types are sparse Mediterranean forest and scrubland. In this area four plots separated by $>5 \mathrm{~km}$ were built. The area of the plots ranged from 2.2 to 4.1 ha, which is within the typical home range area of rabbits (Moseby et al., 2005; Devillarda et al., 2008). To avoid terrestrial predators and rabbit dispersal each plot was surrounded by a 3-m high fence. The plots were set up with $30,30,23$ and 30 artificial warrens, respectively, which were the main refuges for the rabbits. A water and food supply (the latter based on commercial pellets; GARGILL S.L.U., Barcelona, Spain) was placed near each warren. Approximately $80 \%$ of the area of each plot was sown with cereal crops. All the warrens were equipped with efficient capture/recapture devices; approximately $90 \%$ of the rabbits could be captured during one night (unpublished data).

\subsection{Rabbit and pellet surveys}

Surveys were performed in January 2009, eight months after rabbit release, when the populations were completely established and rabbit behavior was similar to that of wild animals (Rouco et al., 2008). We selected this month because in Mediterranean environments significant numbers of juveniles are expected (Moreno et al., 2004). A capture process was undertaken in all the warrens to estimate the number and proportion of adults and juveniles in each of the study plots. All animals $<810 \mathrm{~g}$ (males) or $<750 \mathrm{~g}$ (females) were considered juveniles; animals exceeding these weights were considered adults (Villafuerte, 1994).

To collect rabbit pellets, 30 fixed circular $\left(0.5 \mathrm{~m}^{2}\right)$ stations were randomly placed in each plot (Fernández, 2005). Each pellet station was cleared of rabbit pellets one month before the pellet counting. The pellets collected at each station were stored in separate labeled paper bags, and sorted using $4 \mathrm{~mm}$ and $6 \mathrm{~mm}$ diameter sieves. The proportions of pellets $>6 \mathrm{~mm}$ diameter and $>4 \mathrm{~mm}$ diameter were calculated for comparison with the proportion of adults and juveniles in the populations, according to the method of Rueda et al. (2008).

Standard contingency table tests (chi-square) were used to assess statistical differences between the proportion of pellets $>6 \mathrm{~mm}$ and $>4 \mathrm{~mm}$ (observed variables) and the proportion of adults in each population (expected variables).

\section{Results}

A total of 895 rabbits were captured and 6868 pellets were collected within the four populations. Rabbit numbers varied in each population (35, 281, 325 and 254, respectively), as did the proportion of adults/juveniles (Fig. 1). Overall, in all the populations the proportion of captured adults was significantly different from the proportion of adults estimated on the basis of a pellet diameter $>6 \mathrm{~mm}$ (Table 1; Fig. 1). In three of the four populations the proportion of captured adults was also significantly different from the proportion of adults estimated on the basis of a pellet diameter $>4$ mm (Table 1; Fig. 1).

\section{Discussion and conclusion}

The results of this study show that, in each of the surveyed populations, the proportion of adult rabbits was significantly different from the proportion of pellets $>6 \mathrm{~mm}$ diameter.

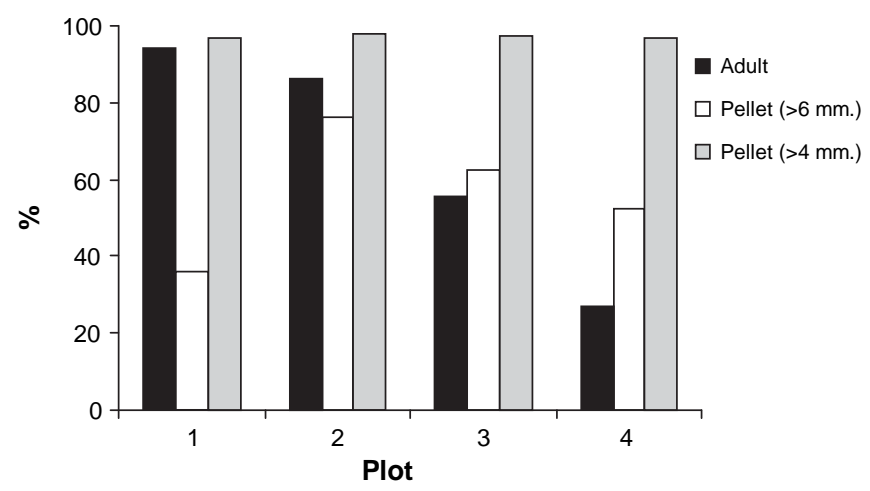

Fig. 1. The proportion of capture adults (black bars), and pellets $>6 \mathrm{~mm}$ (white bars) and $>4 \mathrm{~mm}$ (grey bars) in each of the four rabbit population.

Surprisingly, there was no common pattern among populations; in some cases the estimates of the proportion of adults based on pellet size were underestimates, and in others overestimates. Even though if the proportion of pellets $<6 \mathrm{~mm}$ diameter was similar to the proportion of captured juveniles this would not mean that the pellets $<6 \mathrm{~mm}$ diameter could be assigned to juveniles or vice versa (e.g. to analyze habitat use; Rueda et al., 2008). It may occur, for example, that some adults mainly produce small pellets, as showed by Delibes-Mateos et al. (2009), while some juveniles deposit large pellets, hence balancing in the population the overall proportion of pellets $>6 \mathrm{~mm}$ in diameter. The absence of a common pattern among the populations closely resembles the findings obtained experimentally by Delibes-Mateos et al. (2009).

In addition, according to our results, a $4 \mathrm{~mm}$ threshold was also not useful for differentiating adult and juvenile rabbits. Using this threshold, the proportion of adults was generally overestimated and explains the association between the proportion of pellets $>4 \mathrm{~mm}$ and proportion of adults in population 1 (Table 1; Fig. 1).

Rueda et al. (2009) recommended that animals be kept under semi-natural conditions with respect to both the type of food supply and environmental stressors/conditions. In this study we surveyed four wild rabbit populations living in semi-natural conditions. As was observed in a study conducted using the same experimental design (Rouco, 2008), rabbits in these populations behaved with similar dynamics as wild populations (e.g. in relation to mortalities and population peaks). Our study of four populations varying in population number and with different proportions of adult and juvenile rabbits emulates some of the variability expected in natural populations. However, a potential limitation of the study could be the use of commercial pellets as rabbit feed. However, its consumption was low in January, apparently due to the ready availability of green grass in the study plots.

A second suggestion of Rueda et al. (2009) was that the pellet production by juvenile and adult rabbits should be calculated. In our study 120 counting stations were placed randomly and all

Table 1

Comparison of the proportion of adults with the proportion of pellets $>6 \mathrm{~mm}$ or $>4 \mathrm{~mm}$ in each population.

\begin{tabular}{llcll}
\hline & Population & Chi-Square & Df & P \\
\hline Pellets & 1 & 47.53 & 1 & $* * *$ \\
& 2 & 13.44 & 1 & $* *$ \\
$>6 \mathrm{~mm}$ & 3 & 4.95 & 1 & $*$ \\
& 4 & 58.98 & 1 & $* * *$ \\
\multirow{3}{*}{ Pellets } & 1 & 0.51 & 1 & 0.474 \\
& 2 & 107.97 & 1 & $* * *$ \\
& 3 & 617.48 & 1 & $* * *$ \\
& 3 & 1213.31 & 1 & $* * *$ \\
\hline
\end{tabular}

$* \mathrm{P}<0.05, * * \mathrm{P}<0.01$ and $* * * \mathrm{P}<0.001$. 
sufficient to adequately address our aims. Maybe, a possible limitation of our study is that we may have counted pellets from rabbits that were not captured. However, the four populations were monitored using periodic captures at three-monthly intervals following release, and on all occasions the proportions of the populations captured was very high (unpublished data; see also Rouco, 2008). The number of rabbits captured in our experiment was similar to that expected, based on previous experience (Rouco, 2008). Therefore, we considered that the number of rabbits captured represents widely the real wild rabbit population.

In conclusion, this study provides new evidence that fecal pellet size is not appropriate for determining the age of European wild rabbits. The results suggest that inferring a relationship between the proportion of pellets $>6 \mathrm{~mm}$ diameter and the proportion of adults in a population is erroneous. In addition, the use a pellet diameter threshold of $4 \mathrm{~mm}$ appeared to provide even less accurate results (Fig. 1). We recommend that this technique be validated as part of any study involving its use, as the results obtained can vary greatly among individuals and populations.

\section{Acknowledgements}

C. Rouco and M. Delibes-Mateos were supported by a postdoctoral grant from the regional goverment of Castilla-La Mancha (JCCM), and the European Social Fund. Funding was provided by a technology contract between Doñ ana Biological Station-CSIC and Ingeniería y Gestión del Sur (IPA) and AQUAVID. Thanks go to A. Bertó, G. Macías, C. Marfil, V. Morlanes and C. Pérez for field assistance during rabbit and pellet surveys. And finally special thanks to Drs. Andrew Smith and Heiko G. Rödel for their helpful comments on previous drafts of the manuscript.

\section{References}

Bhadresa, R., 1982. Plant-rabbit interactions on a lowland heath. PhD thesis. King College, London, United Kingdom.

Delibes-Mateos, M., Rouco, C., Villafuerte, R., 2009. Can adult and juvenile rabbits be differentiated by their pellet sizes? Acta Oecol. 35, 250-252.

Dellafiore, C., 2007. Ecología del conejo silvestre (Oryctolagus cuniculus) en un sistema dunar costero. $\mathrm{PhD}$ thesis. University of Seville, Spain.

Devillarda, S., Aubineau, J., Bergerb, F., Leonard, Y., Roobrouckb, A., Marchandeau, S. 2008. Home range of the European rabbit (Oryctolagus cuniculus) in three contrasting French populations. Mamm. Biol. 73, 128-137.

Fernández, N., 2005. Spatial patterns in European rabbit abundance after a population collapse. Landsc. Ecol. 20, 897-910.

Kruuk, H., Conroy, J.W.H., Glimmerween, U., Ouwekerk, E.J., 1986. The use of spraints to survey populations of otters Lutra lutra. Biol. Conserv. 35, 187-194.

Moreno, S., Villafuerte, R., Cabezas, S., Lombardi, L., 2004. Wild rabbit restocking for predator conservation in Spain. Biol. Conserv. 118, 183-193.

Moseby, K.E., De Jong, S., Munro, N., Pieck, A., 2005. Home range, activity and habitat use of European rabbits (Oryctolagus cuniculus) in arid Australia: implications for control. Wildl. Res. 32, 305-311.

Murray, D.L., Roth, D.J., Ellsworth, E., Wirsing, A.J., Steury, T.D., 2002. Estimating low-density snowshoe hare populations using fecal pellet counts. Can. J. Zool. 80, 771-781.

Rouco, C., 2008. Restauración de las poblaciones de conejo de monte y mejora de la gestión para su conservación. PhD thesis. University of Castilla La Mancha, Spain.

Rouco, C., Ferreras, P., Castro, F., Villafuerte, R., 2008. The effect of exclusion of terrestrial predators on short-term survival of translocated European wild rabbits. Wildl. Res. 35, 625-632.

Rueda, M., 2006. Selección de hábitat por herbívoros de diferente tamaño y sus efectos sobre la vegetación. PhD thesis. University of Alcalá, Spain.

Rueda, M., Rebollo, S., Gálvez, L., 2008. Age and season determine European rabbit habitat use in Mediterranean ecosystems. Acta Oecol.34, 266-273.

Rueda, M., Rebollo, S., Gálvez, L., 2009. Response to Delibes-Mateos et al.: pellet size matters. Acta Oecol. 35, 485-487.

Simonetti, J.A., Fuentes, E.R., 1982. Microhabitat use by European rabbits (Oryctolagus cuniculus) in central Chile: are adults and juvenile patterns the same? Oecologia 54, 55-57.

Southgate, R., 2005. Age classes of the greater bilby (Macrotis lagotis) based on track and faecal pellet size. Wildl. Res. 32, 625-630.

Villafuerte, R., 1994. Riesgo de predación y estrategias defensivas del conejo, Oryctolagus cuniculus, en el Parque Nacional de Doñana. PhD Thesis, University of Córdoba, Spain.

Webbon, C.C., Baker, P.J., Harris, S., 2004. Faecal density counts for monitoring changes in red fox numbers in rural Britain. J. Appl. Ecol. 41, 768-779. 